\title{
Dynamics of skin temperature of the knee during physical exercise measured by infrared thermography
}

\author{
by V. Svaic*, B. Jurinjak**, D. Zupanic ${ }^{\star \star}$ and A. Bolaric ${ }^{\star \star}$ \\ *PhD student at University of Zagreb, Faculty of Kinesiology, Zagreb, Croatia, info@kuki-ing.hr \\ ** Mag.Ing.Mech. student at University of Zagreb, Faculty of Mechanical Engineering and Naval Architecture, \\ Zagreb, Croatia
}

\begin{abstract}
The main purpose of this investigation was to analyze the effect of a ten minute low to moderate physical exercise on skin temperature over the knee during the activity period and in the recovery period. Physical activity influences the fall in skin temperature over the working joints during first several minutes of the stationary bicycle exercise, in controlled environment, after which a continuous rise in skin temperature occurs. During the recovery period, after the activity, rise in skin temperature continues above pre-exercise values. It has been established that ten minute recovery period was not sufficient for the stabilization of skin temperature.
\end{abstract}

\section{Introduction}

Infrared thermography is a non-invasive and non-contact method for measuring skin temperature. It allows recording of radiation of skin in a certain area of the infrared spectrum. In the last thirty years infrared thermography has found its application in sports where most of the research has been based on changes in skin temperature during different types of exercise and the different microclimate conditions $[1,2,3]$. Taking into consideration that the skin temperature can be a result of deep tissue metabolic activities like circulatory system changes, inflammatory or degenerative process, therefore thermography represents a means for evaluation of bone, muscle, ligament and neurological structures in the human body. Physical activity increases central body temperature due to the higher production of energy in involved musculature during physical work [4]. Becher et al. [5] used a probe to measure intra-articular temperature of knee during running on a treadmill for 60 minutes in a controlled environment and determined increase in temperature by $6.1^{\circ} \mathrm{C}$, with values $31.4^{\circ} \mathrm{C}$ before and $37.5{ }^{\circ} \mathrm{C}$ after the activity. Rise in central body temperature during low to moderate physical exercise activates active vasodilatation mechanisms and sweating in order to dissipate produced heat from the body [6]. Thus the skin temperature is determined by multiple factors such as a combination of conduction of the heat from the working musculature, perfusion of the blood and heat exchange between human body and the environment [7]. Previous studies have found a decrease in temperature on the surface of the skin during physical activity and an increase in temperature during the recovery phase $[3,4,7,8,9]$. However, effect of physical exercise on the changes of temperature of the skin above working joints has still not been researched, according to the authors' knowledge. Therefore the main object of this investigation was to analyze the effect of a ten minute low to moderate physical exercise on skin temperature over the knee during the activity period and in the recovery period. 


\section{Methods}

Thirty four student volunteers were involved in this experiment (27 male and 7 female) with the mean age 19.3 years. The experiment took part at the Thermo Laboratory of Faculty of Mechanical Engineering and Naval Architecture of University of Zagreb. The participants were all healthy and had signed an informed written consent. The students were asked not to eat or drink caffeine before taking part in the experiment. During the experiment the subjects were dressed in shorts and T-shirt. Stationary bicycle was placed in the climatic chamber where the experiment was conducted and students participated in the experiment one at a time. Mean temperature in the chamber was $24.7( \pm 1.1){ }^{\circ} \mathrm{C}$ and relative humidity 19.9 $( \pm 2.8) \%$. After acquiring basic information of participants, the experiment started with the ten minute acclimatization phase in a sitting position. General information of the subjects and climatic conditions can be seen in table 1.

Table 1. Descriptive statistics

\begin{tabular}{|l|c|c|c|c|c|c|}
\hline & $N$ & Range & Minimum & Maximum & Mean & $S D$ \\
\hline Age (years) & 34 & 3.0 & 18.0 & 21.0 & 19.3 & 0.84 \\
\hline Height (cm) & 34 & 38.0 & 157.0 & 195.0 & 179.4 & 8.4 \\
\hline Weight (kg) & 34 & 54.7 & 52.8 & 107.5 & 76.2 & 11.7 \\
\hline BMI & 34 & 14.4 & 18.4 & 32.8 & 23.6 & 2.9 \\
\hline Ambient temperature (C) & 34 & 4.3 & 21.7 & 26.0 & 24.7 & 1.1 \\
\hline Relative humidity (\%) & 34 & 12.4 & 16.1 & 28.5 & 19.9 & 2.8 \\
\hline
\end{tabular}

*BMI - body mass index, SD - standard deviation

The experiment lasted for a total of 30 minutes with ten minute rest period (RES), ten minute activity period (ACT) and 10 minute recovery period (REC). During the rest and recovery period participants stood still in front of the camera, and during the activity period subject were instructed to ride a stationary bicycle continuously in a low to moderate physical strain with the heart rate $(\mathrm{HR})$ of $65( \pm 5) \%(117-136 \mathrm{HR})$ of a maximal heart rate (193-195 HR) predicted by their age [10]. Once heart rate goal was achieved it was supposed to be kept for the whole activity period. Polar heart beat monitor RS300X was used to measure heart rate. We used the standardized methodological procedure for acquiring thermograms of the region of interest (ROI), the Glamorgan protocol, in order to get the most accurate results [11]. A thermogram of the anterior side of the knees was recorded at the end of every minute of the experiment with the total of thirty thermograms being analyzed for each knee (figure 2). Three independent examiners provided results after a quantitative analysis of the thermograms and the average temperature of the three examiners at every point (minute) of the recording was then used as a final result. A high objectivity was calculated among the examiners with Cronbach a 0.98 during all three periods. Flir SC2000 infrared thermocamera was used for recoding thermograms and ThermaCAM Researcher 2002 Application (Flir Systems AB, Sweden) was used for the quantitative analysis. T-test for paired sample was used to test the differences between temperatures. 


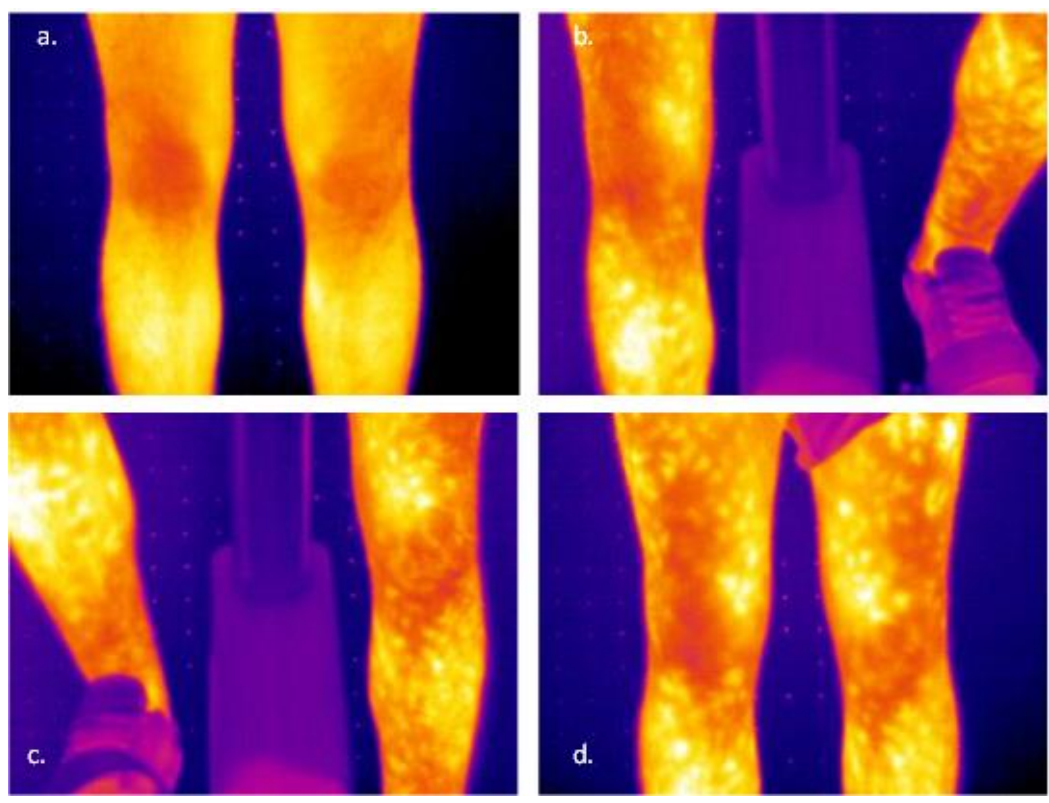

Fig. 1. Termograms of the knees during rest (a), activity (b, c) and recovery period (d).

\section{Results}

The dynamics of mean skin temperature changes of the knees are shown in the figure 2, for the 34 subjects involved in this study. At $\mathrm{t}=10 \mathrm{~min}$ the participants started pedaling and at $\mathrm{t}=20$ they stopped with the exercise. As can be seen from the graph a fall in skin temperature begins with the start of the activity and it continues during the first three minutes of low to moderate stationary bicycle exercise.

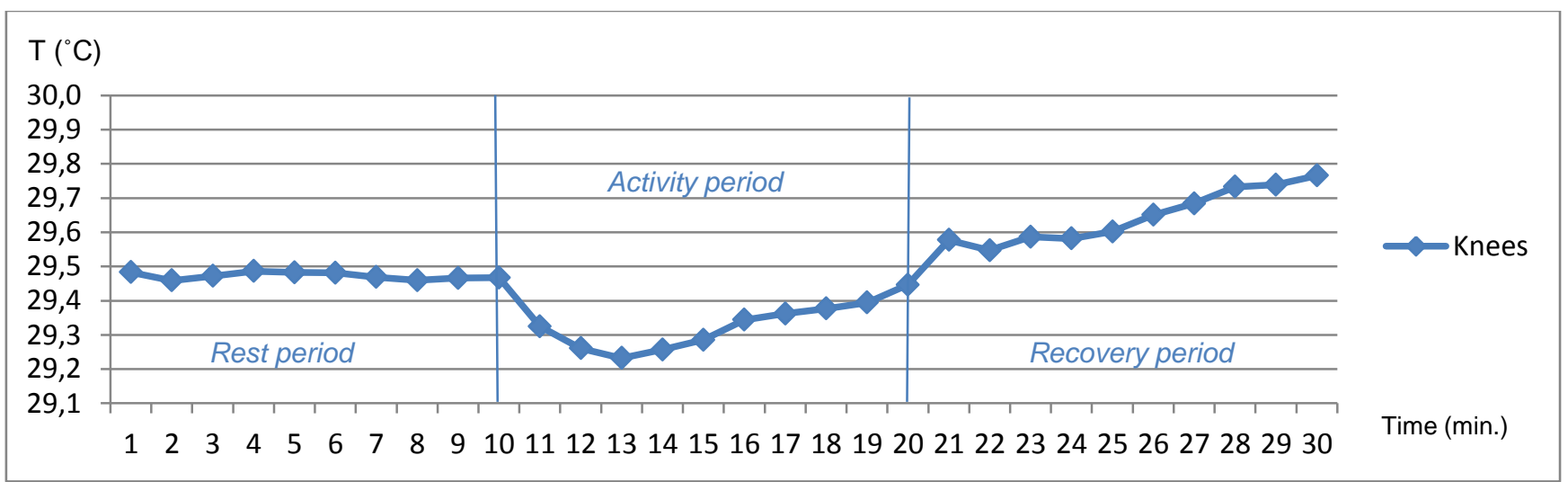

Fig. 2. Mean skin temperature $\left({ }^{\circ} \mathrm{C}\right)$ of the knees during 30 minutes of measuring

Mean temperature drop from $\mathrm{t}=10 \min \left(\mathrm{T}_{\min 10}=29.5{ }^{\circ} \mathrm{C}\right)$ to $\mathrm{t}=13 \mathrm{~min}\left(\left(\mathrm{~T}_{\min 13}=29.2{ }^{\circ} \mathrm{C}\right)\right.$ was $-0.3^{\circ} \mathrm{C}$ (table 2$)$. After which a gradual rise in skin temperature occurs with a temperatures change of $0.6{ }^{\circ} \mathrm{C}$ from $\mathrm{t}=13 \min \left(\mathrm{T}_{\min 13}=29.2{ }^{\circ} \mathrm{C}\right)$ to $\mathrm{t}=30 \mathrm{~min}$ $\left(T_{\min 30}=29.8^{\circ} \mathrm{C}\right)$. During the recovery period, after the activity, rise in skin temperature continues above pre-exercise values and at the end of the experiment a gradual linear rise can still be seen. It has been established that ten minute recovery 
http://dx.doi.org/10.21611/qirt.2014.141

period was not sufficient for the stabilization of skin temperature surrounding knees after a low to moderate physical strain lasting for ten minutes.

Table 2. Mean skin temperature $\left({ }^{\circ} \mathrm{C}\right)$ of the knees over time (1-30 min.)

\begin{tabular}{|c|c|c|c|c|c|c|c|}
\hline \multirow[t]{2}{*}{ Time (min.) } & \multirow{2}{*}{$\frac{N}{\text { Statistic }}$} & \multirow{2}{*}{$\begin{array}{l}\text { Range } \\
\text { Statistic }\end{array}$} & \multirow{2}{*}{$\begin{array}{c}\text { Minimum } \\
\text { Statistic }\end{array}$} & \multirow{2}{*}{$\begin{array}{c}\text { Maximum } \\
\text { Statistic }\end{array}$} & \multicolumn{2}{|c|}{ Mean } & \multirow{2}{*}{$\begin{array}{c}S D \\
\text { Statistic }\end{array}$} \\
\hline & & & & & Statistic & Std. Error & \\
\hline t1 & 34 & 4,4 & 27,3 & 31,7 & 29,5 & ,20 & 1,16 \\
\hline t2 & 34 & 4,3 & 27,4 & 31,7 & 29,5 & ,20 & 1,15 \\
\hline t3 & 34 & 4,4 & 27,3 & 31,7 & 29,5 & ,20 & 1,17 \\
\hline t4 & 34 & 4,1 & 27,5 & 31,6 & 29,5 & 19 & 1,12 \\
\hline t5 & 34 & 4,0 & 27,5 & 31,5 & 29,5 & 19 & 1,12 \\
\hline t6 & 34 & 4,0 & 27,6 & 31,6 & 29,5 & 19 & 1,10 \\
\hline t7 & 34 & 4,1 & 27,5 & 31,6 & 29,5 & 19 & 1,11 \\
\hline t8 & 34 & 4,2 & 27,4 & 31,6 & 29,5 & ,19 & 1,09 \\
\hline t9 & 34 & 4,3 & 27,4 & 31,7 & 29,5 & ,19 & 1,11 \\
\hline t10 & 34 & 4,2 & 27,5 & 31,7 & 29,5 & ,19 & 1,09 \\
\hline$t 11$ & 34 & 4,3 & 27,3 & 31,6 & 29,3 & 19 & 1,10 \\
\hline $\mathrm{t} 12$ & 34 & 4,4 & 27,1 & 31,5 & 29,3 & 19 & 1,09 \\
\hline$t 13$ & 34 & 4,0 & 27,1 & 31,1 & 29,2 & ,19 & 1,10 \\
\hline t14 & 34 & 4,0 & 27,1 & 31,1 & 29,3 & 19 & 1,11 \\
\hline t15 & 34 & 4,0 & 27,2 & 31,2 & 29,3 & 19 & 1,09 \\
\hline t16 & 34 & 4,0 & 27,2 & 31,2 & 29,4 & 19 & 1,08 \\
\hline t17 & 34 & 4,0 & 27,3 & 31,3 & 29,4 & 18 & 1,07 \\
\hline t18 & 34 & 4,1 & 27,4 & 31,5 & 29,4 & 19 & 1,08 \\
\hline t19 & 34 & 4,1 & 27,3 & 31,4 & 29,4 & ,18 & 1,07 \\
\hline t20 & 34 & 4,3 & 27,3 & 31,6 & 29,5 & ,19 & 1,09 \\
\hline t21 & 34 & 4,3 & 27,5 & 31,8 & 29,6 & ,19 & 1,10 \\
\hline t22 & 34 & 4,4 & 27,5 & 31,9 & 29,5 & 19 & 1,08 \\
\hline t23 & 34 & 4,6 & 27,5 & 32,1 & 29,6 & 19 & 1,12 \\
\hline t24 & 34 & 4,7 & 27,5 & 32,2 & 29,6 & ,20 & 1,14 \\
\hline t25 & 34 & 4,8 & 27,6 & 32,4 & 29,6 & ,20 & 1,14 \\
\hline t26 & 34 & 4,8 & 27,7 & 32,5 & 29,7 & ,20 & 1,14 \\
\hline t27 & 34 & 5,3 & 27,4 & 32,7 & 29,7 & ,20 & 1,18 \\
\hline t28 & 34 & 5,3 & 27,5 & 32,8 & 29,8 & ,20 & 1,17 \\
\hline t29 & 34 & 5,3 & 27,5 & 32,8 & 29,8 & 20 & 1,18 \\
\hline t30 & 34 & 5,3 & 27,6 & 32,9 & 29,8 & ,21 & 1,20 \\
\hline
\end{tabular}

\footnotetext{
* $\mathrm{N}$ - number of participants SD - standard deviation
} 
Table 3. Mean temperature of both knees during ten minute recordings of each period

\begin{tabular}{|c|c|c|c|c|c|c|c|c|c|c|}
\hline Period & $N$ & Range & Minimum & Maximum & Mean & $S D$ & Skewness & Std.Error & Kurtosis & Std.Error \\
\hline 1. Rest - $T_{\text {res }}\left({ }^{\circ} \mathrm{C}\right)$ & 34 & 4.1 & 27.5 & 31.6 & 29.5 & 1.11 & -0.337 & 0.403 & $-0,793$ & 0.788 \\
\hline 2. Activity - $T_{\text {act }}\left({ }^{\circ} \mathrm{C}\right)$ & 34 & 3.8 & 27.3 & 31.1 & 29.3 & 1.06 & -0.379 & 0.403 & $-0,394$ & 0.788 \\
\hline 3. Recovery - $T_{\text {rec }}\left({ }^{\circ} \mathrm{C}\right)$ & 34 & 4.8 & 27.6 & 32.4 & 29.6 & 1.13 & 0.054 & 0.403 & 0,127 & 0.788 \\
\hline
\end{tabular}

* $T_{\text {res }}-$ mean rest temp., $T_{\text {act }}-$ mean activity temp., $T_{\text {rec }}-$ mean recovery temp., $\mathrm{N}$ - number of participants SD - standard deviation

Testing of normality of the data using skewness and kurtosis values (table 3) and analysing histograms and Q-Q plots showed that knee temperatures were normaly distributed which made it possible to proceed with quantitative analysis. Three separate t-tests for paired samples were used to test the differences between mean ten minute temperature of the knees during rest and activity period, rest and recovery period, activity and recovery period. The results showed significant difference between mean rest and mean activity temperature $(t=2.422 ; p=0.021)$, mean activity and mean recovery temperature $(t=-4.188 ; p=0.000)$ but no statisticaly significant difference between mean rest and mean recovery temperatures $(t=-1.452 ; p=0.152)$ of the knees (table 4$)$. The level of significance was set to $p<0.05$.

Table 4. Results of t-tests for mean temperature values

\begin{tabular}{|c|c|c|c|c|c|}
\hline & Mean & $S D$ & $d f$ & $t$ & $p$ \\
\hline Pair 1 $T_{\text {res }}-T_{\text {act }}$ & 0.150 & 0.361 & 33 & 2.422 & 0.021 \\
\hline Pair 2 $T_{\text {res }}-T_{\text {rec }}$ & -0.171 & 0.685 & 33 & -1.452 & 0.156 \\
\hline Pair 3 $T_{\text {act }}-T_{\text {rec }}$ & -0.321 & 0.446 & 33 & -4.188 & 0.000 \\
\hline
\end{tabular}

* $T_{\text {res }}-$ mean rest temp., $T_{\text {act }}-$ mean activity temp., $T_{\text {rec }}-$ mean recovery temp., SD - standard deviation, df - degrees of freedom, $\mathrm{t}$ - test value, $\mathrm{p}$ - value

\section{Discussion}

Our study showed that physical activity influences the fall in skin temperature over the working joints during first three minutes of the stationary bicycle exercise, in the controlled environment, after which a continuous rise in skin temperature occurs. During the recovery period, after the activity, rise in skin temperature continues above pre-exercise values. Similar results were found by Demachi et al. [6] during a thirty minute exercise on a bicycle ergometer with fixed exercise loads at $20 \%$ (about $50 \mathrm{~W}$ ) and $50 \%$ (about $120 \mathrm{~W}$ ) of VO2 peak, under three room temperature conditions (20, 24, and $28^{\circ} \mathrm{C}$ ) measured with thermocouple probes at several body sites. This initial fall in skin temperature is associated with a higher demand of blood flow in the working musculature leading to a skin reflex vasoconstriction response of the blood vessels [7]. As the body temperature rises, the thermal demand predominates and the skin vessels dilate, increasing heat conduction to the skin. Active vasodilation occurres when the internal temperature or deep tissue temperature in exercising muscle exceeds a specific level [6]. In our investigation a temperature drop occurred by a mean $\Delta \mathrm{T}_{\mathrm{t} 10-13}=-0.08{ }^{\circ} \mathrm{C} / \mathrm{min}$ during a low to moderate continuous exercise with a $65 \%$ of a maximal heart rate ( $\left.\mathrm{HR}_{\max }\right)$. A moderate rise in skin temperature was observed during the following seven minutes of the activity period with mean $\Delta \mathrm{T}_{\mathrm{t} 13-20}=0.03{ }^{\circ} \mathrm{C} / \mathrm{min}$ and through the resting period by a mean $\Delta \mathrm{T}_{\mathrm{t} 20-30}=0.03{ }^{\circ} \mathrm{C} / \mathrm{min}$. Highest temperature jump of $0.1{ }^{\circ} \mathrm{C}$ can be seen in the first minute of recovery period from $t=20\left(T_{\min 20}=29.5^{\circ} \mathrm{C}\right)$ to $t=21\left(T_{\min 20}=29.6{ }^{\circ} \mathrm{C}\right)$. Similar to the investigation of Chudecka \& 
Lubkowska [4], who found a decrease in skin temperature of the upper limbs immediately after completing the 90-minute volleyball training session, we found statistical difference between a mean skin temperature before activity and during the cycling exercise. Zaïdi et al. [12] on the other hand found an increase in the skin temperature of the whole body after subjects performed short swimming tests lasting for 63-82 seconds. These results imply a rise in skin temperature during first couple of minutes of a short sprint exercise. A level of fall in skin temperature during first several minutes of continuous exercise seems to correlate with the initial skin temperature [7] and later level of increase with the intensity of the activity [5,6,12]. Although no significant difference was found between meant resting temperature and mean recovery temperature in this study, it is clear from the figure 2 that a continuous rise of skin temperature occurs above pre-exercise level with the temperature rise from $t=10 \min \left(T_{\min 10}=29.5^{\circ} \mathrm{C}\right)$ to $t=30 \min \left(\left(T_{\min 30}=29.8^{\circ} \mathrm{C}\right)\right.$ of $0.3^{\circ} \mathrm{C}$.

\section{Conclusion}

These findings suggest that the dynamics of skin temperature over working joints act similar to the dynamics of skin temperature over active musculature and non-active parts of the body, which was found in previous studies [1,3,4,7,12], although absolute temperature differences are slightly smaller due to the smaller area of muscle tissue around joints. Acquiring a mapping of skin temperatures above the knee can help us to better understand the mechanisms of thermoregulation of the skin and provide us the possibility to quantify the effect of physical exercise on the dynamics of those temperature changes. Future research should be directed towards the effects of different types of physical exercise in changes of the skin temperature.

\section{REFERENCES}

[1] Akimov, E.B. \& Son'kin, V.D., "Skin temperature and lactate threshold during muscle work in athletes". Human Physiology, vol. 37(5), p.p. 621-628, 2011.

[2] Čoh, M. i Širok, B., "Use of the thermovision method in sport training". Physical Education and Sport, vol. 5(1), p.p. 85-94, 2007.

[3] Merla, A., Mattei, P.A., Di Donato, L. \& Romani, G.L., "Thermal imaging of cutaneous temperature modifications in runners during graded exercise". Annals of biomedical engineering, vol. 38(1), p.p. 158-163, 2010.

[4] Chudecka, M. \& Lubkowska, A., "The use of thermal imaging to evaluate body temperature changes of athletes during training and a study on the impact of physiological and morphological factors on skin temperature". Human Movement, vol. 13(1), p.p. 33-39, 2012.

[5] Becher, C., Springer, J., Feil, S., Cerulli, G. \& Paessler, H.H., "Intra-articular temperatures of the knee in sports - an in-vivo study of jogging and alpine skiing". BMC Musculoskeletal Disorders, 9:46, 2008.

[6] Demachi, K., Yoshida, T., Kume, M., Tsuji, M. \& Tsuneoka, H., "The influence of internal and skin temperatures on active cutaneous vasodilation under different levels of exercise and ambient temperatures in humans". International Journal of Biometeorology, vol. 57(4), p.p. 589-596, 2013.

[7] Zontak, A., Sideman, S., Verbitsky, O. \& Beyar, R., "Dynamic thermography: analysis of hand temperature during exercise. Annals of Biomedical Engineering, vol. 26(6), p.p. 988-993, 1998.

[8] Chudecka, M. \& Lubkowska, A., "The use of thermal imaging to evaluate body temperature changes of athletes during training and a study on the impact of physiological and morphological factors on skin temperature". Human Movement, vol. 13(1), p.p. 33-39, 2012.

[9] Arfaoui, A., Polidori, G., Taiar, R., \& Popa, C., "Infrared thermography in sports activity". In R. V. Prakash (Ed.), Infrared Thermography, pp. 141-168, InTech, 2012.

[10] Tanaka, H., Monahan, K.D. \& Seals, D.R., "Age-predicted maximal heart rate revisited", Journal of the American College of Cardiology, vol. 37(1), p.p. 153-156, 2001.

[11] Ammer, K., "The Glamorgan Protocol for recording and evaluation of thermal images of the human body". Thermology international, vol. 18, p.p. 125-144, 2008.

[12] Zaïdi, H., Taïar, R., Fohanno, S. \& Polidori, G., "The influence of swimming type on the skin-temperature maps of a competitive swimmer from infrared thermography". Acta of Bioengineering and Biomechanic, vol. 9 (1), p.p. 47-51, 2007. 